\title{
Comparison of Leavening Ability of Kluyveromyces lactis in Different Bread Dough Formulations
}

\section{Bekir Gökçen Mazı}

Department of Food Engineering, Faculty of Agriculture, Ordu University, Cumhuriyet Campus PK 52200 Altınordu/Ordu, Turkey E-mail:bgmazi@odu.edu.tr, ORCID: https://orcid.org/0000-0003-3478-6243

\begin{tabular}{|c|c|}
\hline A R T I C L E I N F O & A B S T R A C T \\
\hline $\begin{array}{l}\text { Received : 20/06/2018 } \\
\text { Accepted : 23/11/2018 }\end{array}$ & $\begin{array}{l}\text { The aim of this study was to evaluate the dough proofing activity of Kluyveromyces lactis (ATCC } \\
8585 \text { ) in different dough formulations and to compare it with the commercial active dry bakery } \\
\text { yeast Saccharomyces cerevisiae. Leaving ability of yeasts was tested in lean and rich dough. For } \\
\text { both cultures, lean and rich dough mixtures containing } 0.3 \mathrm{~g} \text { of yeast biomass (on dry weight } \\
\text { basis) and wheat flour in } 15 \mathrm{ml} \text { of water was prepared. Rich dough contained also either } 2.0 \mathrm{~g} \text { of } \\
\text { sucrose, } 2.0 \mathrm{~g} \text { of lactose or } 2.5 \mathrm{~g} \text { of whey powder. Dough mixtures were incubated at } 29^{\circ} \mathrm{C} \text { and } \\
\text { volume increase was recorded every } 15 \mathrm{~min} \text {. We determined that Kluyveromyces lactis had higher } \\
\text { volume and leavening rates compared to commercial bakery yeast strain in lactose-rich or whey- } \\
\text { rich dough. These results demonstrated the potential of Kluyveromyces lactis yeast strain as a } \\
\text { suitable culture for whey fortified bread making. }\end{array}$ \\
\hline
\end{tabular}

Bread dough

Kluyveromyces lactis

Leavening

Lactose

Whey

(c) $($ ) (9) This work is licensed under Creative Commons Attribution 4.0 International License

\section{Introduction}

Bakery products are generally rich in carbohydrates; besides poor in proteins. Bread is widely consumed wheat based baked product. There are many studies in literature investigating the possibility of improving nutritional properties of bread with the addition of different ingredients to bread formulation (Istianah et al., 2018; Zhou et al., 2018; Tang and Liu 2017; Ammar et al., 2011; Indrani et al., 2007; Ribotta et al., 2005; Chavan and Kadam 1993). Whey, the by-product of the dairy industry, is known to be rich in high-quality protein. Therefore, enrichment of wheat-based foods with whey increases their nutritional content (Zhou et al., 2018).

Whey is used in various food products (bakery, confectionery, pastry, meat, ice creams and yoghurt) for many purposes (to improve nutritional value, taste, texture and appearance) (Królczyk et al., 2016). Whey proteins addition effects on some rheological properties of dough were investigated by some authors (Ammar et al., 2011; Sudha et al., 2011; Indrani et al., 2007; Kenny et al., 2001). Whey contains soluble proteins ( $\beta$ lactoglobulin, $\alpha$-lactalbumin and lactoferrin), lactose, fat, vitamins and minerals (Zhou et al., 2018). Lactose, the major component of the whey, enhances the Maillard reaction and flavour and improves emulsification, crumb structure and taste of bakery products. However, high amounts of lactose found in the whey may cause digestive problems for lactose intolerance individuals. Lactose can be hydrolysed enzymatically or microbiologically to overcome this problem. The most practical way to solve this problem in whey enriched bakery products seems to be the use of yeast that can use lactose as a carbon source. The yeast Saccharomyces cerevisiae is the most widely used microorganism in fermentation of bread, however it does not metabolize lactose. Kluyveromyces lactis and Kluyveromyces marxianus are the two well-known species within the genus Kluyveromyces and both can use lactose as a carbon source (Schaffrath and Breunig 2000; Rubio-Texeira 2006). K. lactis had been thought to be closely related to $K$. marxianus, but at present molecular studies showed that, DNA complementarity is less than $15-20 \%$ which shows that they are distinct species (Johannsen and van der Walt, 1978; Johannsen 1980; Fuson et al., 1987; Vaughan-Martini and Martini 1987). Compared to the $S$. cerevisiae (grows on D-glucose, Dgalactose, sucrose, maltose, raffinose), Kluyveromyces lactis assimilates a wider range of substances. Although, $K$. lactis can grow on D-glucose, D-galactose, L-sorbose, sucrose, maltose, cellobiose, raffinose presence. The 
growth rate on lactose is quite high and lactose is the excellent carbon source for its growth (Pearson et al., 1990; Wesolowski-Louvel et al., 1996). The possibility of using strains of the genus Kluyveromyces as bakery yeast was evaluated by some researchers. Caballero et al. (1995), investigated the possibility of using strains of $K$. marxianus as bakery yeast and compared it with two strains of Saccharomyces cerevisiae. They stated that $K$. marxianus strains had superior proofing activity in lactose-rich or whey-rich doughs compared to commercial bakery yeast strains. However, there was no difference between these species in terms of the flavor of the bread. Plessas et al. (2008a,b) used mixed culture of Kluyveromyces marxianus, Lactobacillus delbrueckii ssp. bulgaricus and L. helveticus for sourdough bread making. The results revealed that mixed culture leavened bread had a firmer texture, lower acidity and retained its moisture and freshness for longer period of time compared to bakery yeast bread. Dimitrellou et al. (2009), evaluated the use of thermally-dried Kluyveromyces marxianus as bakery yeast and stated that there are not significant differences in the profile of aroma-related compounds and overall quality of the tested samples. Effect of different proportions of Kluyveromyces lactis and Saccharomyces cerevisiae (0:100, 100:0, 75:25, $50: 50,25: 75)$ on the bread dough rise capacity was investigated by Ramachandra et al. (2009). The results showed that commercial bakery yeast S.cerevisiae could successfully be replaced by $K$. lactis up to an extent of $50 \%$ with better leavening properties in terms of dough volume. The main objective of this study is to investigate the dough proofing activity of Kluyveromyces lactis in different bread dough formulations and to compare obtained results with the results of conventional bakery yeast Saccharomyces cerevisiae.

\section{Materials and Methods}

\section{Materials}

Yeast extract and peptone were obtained from Merck Chemical Co. Lactose, sucrose; ethanol and Orthonitrophenyl-b-D-galactopyranoside (ONPG) were obtained from Sigma Chemical Co. Whey powder (containing $80 \%$ lactose, $10 \%$ protein, $1 \%$ fat) was obtained as a gift of Enka dairy plant (Konya, Turkey). Commercial flour (Type 650; containing 9.0\% proteins, $72.0 \%$ carbohydrates, $1.6 \%$ fat and $3.5 \%$ fiber), used for bread making, was obtained from local market. Other chemicals $\quad\left(\beta\right.$-mercatpoethanol, $\quad \mathrm{Na}_{2} \mathrm{HPO}_{4} \cdot 2 \mathrm{H}_{2} \mathrm{O}$, $\mathrm{NaH}_{2} \mathrm{PO}_{4}, \mathrm{Na}_{2} \mathrm{CO}_{3}, \mathrm{KCl}, \mathrm{MgSO}_{4} \cdot 7 \mathrm{H}_{2} \mathrm{O}, \mathrm{H}_{2} \mathrm{SO}_{4}$, ) used were of analytical grade. The water used to prepare dough mixtures was distilled.

\section{Yeast Strains and Culture Conditions}

Kluyveromyces lactis ATCC 8585 (from Industrial Yeast Collection of Dipartimento di Biologia Vegetale di Perugia (BDVPG), Italy) and Saccharomyces cerevisiae from commercial active dry bakery yeast as a reference were used in this study. Kluyveromyces lactis was aerobically grown in $1000 \mathrm{ml}$ Erlenmeyer flaks with $200 \mathrm{ml}$ of culture medium at $29^{\circ} \mathrm{C}$ in an orbital shaker (200 rpm). Culture medium was composed of $1 \%$ yeast extract, $2 \%$ peptone and $2 \%$ lactose. After incubation, cultured cells were harvested by centrifugation (10000xg, $15 \mathrm{~min})$. Dry weight of the cultured cells was determined according to protocol by Mazı (2010).

\section{Consumption of Lactose and Production of Ethanol}

Change of lactose and ethanol concentration of the media during growth was analysed by HPLC (LKB, USA) using an organic acid analysis column (Phenomenex, Torrance, CA, USA), and refractive index detector (RI 2000 Schambeck, Bad Honnef, Germany). The column was kept at $50-65^{\circ} \mathrm{C}$ and was eluted with 5 $\mathrm{mM} \mathrm{H} \mathrm{SO}_{4}$. The detector cell was kept at $35^{\circ} \mathrm{C}$. Signal from detector was processed by Chromasimple data acquisition software (Dizge Analitik, Turkey). Lactose and ethanol standard solution of known concentrations were used for calibration (Büyükkileci 2007). Lactose consumption (g lactose/L.h.mg dry cell) and ethanol production rates ( $g$ ethanol/L.h.mg dry cell) were calculated.

\section{Enzyme Assays}

$\beta$-Galactosidase activity was determined according to protocol by Platt et al. (1972). One unit of enzyme (EU) is defined as $1 \mu \mathrm{g}$ of orthonitrophenol (ONP) from ortnonitrophenyl- $\beta$-D-galactopyranoside (ONPG) released at $30^{\circ} \mathrm{C}$ per minute per one $\mathrm{mg}$ of yeast (dry basis) under the assay conditions. Kluyveromyces lactis cells were disrupted according to protocol by Mazı (2010). Celldebris is removed by centrifugation at $10000 \mathrm{xg}$ for 10 $\mathrm{min}$ and the cell-free/protein rich extract recovered in the supernatant was used for the enzyme assays. A $\beta$ galactosidase containing solution was appropriately diluted for quantification by UV-Vis absorbance, and 0.1 $\mathrm{ml}$ of this solution was added into $0.9 \mathrm{ml}$ of Z-buffer $(0.1$ $M$ sodium phosphate buffer, $10 \mathrm{mM} \mathrm{KCl}$, and $1 \mathrm{mM}$ $\mathrm{MgSO}_{4}, \mathrm{pH}$ 7.0), with $50 \mathrm{mM} \beta$-mercaptoethanol. In order to start the reaction $0.2 \mathrm{ml}$ of a $4 \mathrm{mg} / \mathrm{ml}$ ONPG solution in Z-buffer was then added to $1 \mathrm{ml}$ of this enzyme mixture. The reaction was allowed to proceed for $15 \mathrm{~min}$ at $30^{\circ} \mathrm{C}$. The reaction was then stopped by addition of $0.5 \mathrm{ml} 1 \mathrm{M} \mathrm{Na} 2 \mathrm{CO}$ into the reaction medium. The absorbance was measured at $420 \mathrm{~nm}$ against an appropriate enzyme blank. The molar extinction coefficient $(\varepsilon)$ of orthonitrophenol under these conditions was $4500 \mathrm{M}^{-1} \mathrm{~cm}^{-1}$.

\section{Dough Preparation and Leavening Ability}

Leavening ability of the yeasts was determined by the cylinder method (Okagbue, 1988). For both cultures, lean and rich dough mixtures containing $0.3 \mathrm{~g}$ of yeast biomass (on dry weight basis) and wheat flour in $15 \mathrm{ml}$ of water for every $20 \mathrm{~g}$ of wheat flour was prepared. Rich doughs contained also either $2 \mathrm{~g}$ of sucrose, $2 \mathrm{~g}$ of lactose or $2.5 \mathrm{~g}$ of whey powder. Dough mixture was poured into a 100 $\mathrm{ml}$ measuring cylinder and initial volume was read. Dough mixture was incubated at $29^{\circ} \mathrm{C}$ and volume increase was recorded every $15 \mathrm{~min}$. Maximum leavening rate $(\mathrm{ml} / \mathrm{h})$ of yeasts, defined as the highest positive slope of the leavening profile of dough within $210 \mathrm{~min}$, was calculated for each dough. All experiments were carried out in triplicate, and error bars are reported to indicate the value of the standard error. 


\section{Statistical Analysis}

All drying experiments were conducted in triplicate. The data were assessed by analysis of variance (ANOVA). Differences among individual means were compared by using Tukey Comparison test $(\mathrm{P}<0.05)$ (MINITAB, Version 14).

\section{Results and Discussion}

The aim of this study was to evaluate the dough proofing activity of Kluyveromyces lactis and to compare it with commercial active dry bakery yeast Saccharomyces cerevisiae. Specific $\beta$-galactosidase activity, lactose consumption and ethanol production rates during $K$. lactis biomass production were shown in Figure 1. K. lactis biomass was harvested after 12 hours of fermentation where maximum specific activity of $\beta$ galactosidase was measured.

Both yeasts were tested under the same conditions for comparison purposes. Data obtained for leavening activity in lean dough (a) and rich doughs (b, c and d for sucrose, lactose and whey, respectively) were displayed in Figure 2. Statistical analyses showed that the yeast type, dough formulation and the interaction of yeast type and dough formulation were all important factors affecting the maximum leavening rate and the maximum volume of dough (Table 1).

For the yeast $S$. cerevisiae, the leavening rate of sucrose containing dough was significantly higher as compared to the lactose and whey containing ones. Oda and Ouchi (1990) stated that fermentation of lean dough by $S$. cerevisiae started with pre-existed sugars in the wheat flour (glucose, fructose and sucrose) and continued with maltose. The performance of $S$. cerevisiae in lean, lactose-rich, and whey-rich doughs was pretty much same for the reason that it cannot metabolize lactose. On the other hand, the highest leavening ability of K. lactis was observed in lactose and whey containing doughs. It can be seen in Figure 2 (a) and (b) that the performances of the two strains were better in sucrose-rich dough than in lean dough. As the predictable result, both yeast strains were able to metabolize sucrose efficiently. The fermentation of sucrose-reach dough by K.lactis was slower than by $S$. cerevisiae. In other words the sucrose degradation by $S$. cerevisiae was faster. Maximum volume of S.cerevisiae and K.lactis added doughs were 108.3 and $82.7 \mathrm{ml}$ for lean doughs, 128.7 and $113.3 \mathrm{ml}$ for sucrose containing doughs, 114.0 and $142.3 \mathrm{ml}$ for lactose containing doughs, 118.3 and $121.0 \mathrm{ml}$ for whey containing doughs, respectively (Table 2).

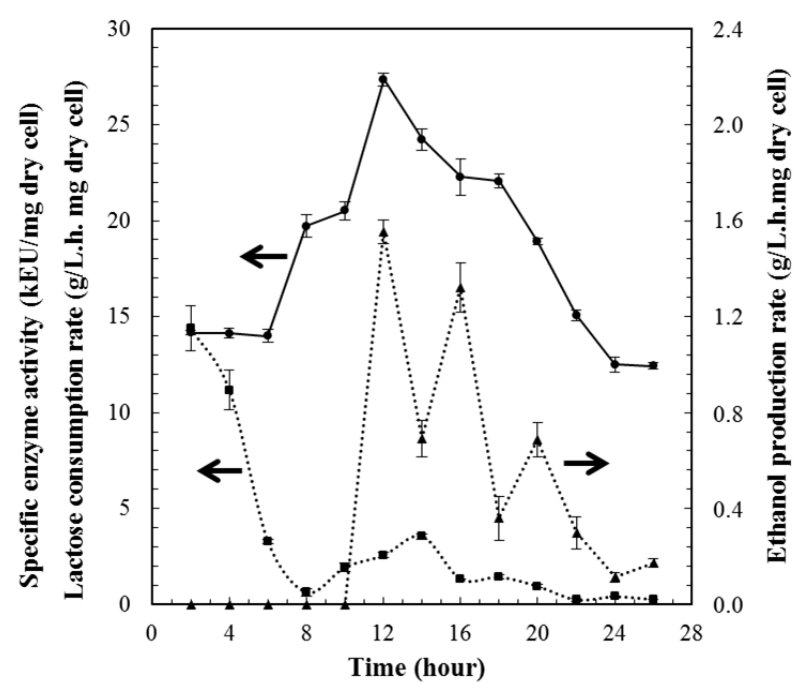

Figure 1 Specific enzyme activity of $\beta$-galactosidase $(\bullet)$ and lactose consumption $(\boldsymbol{\square})$, ethanol production rate $(\boldsymbol{\Delta})$ of the K. lactis during growth

Table 1 ANOVA showing the effects of yeast type, dough formulation and interaction term on maximum leavening rate and maximum volume

\begin{tabular}{|c|c|c|c|c|c|c|}
\hline \multirow{2}{*}{ Source } & \multicolumn{3}{|c|}{ Max. Leavening Rate $\left(\mathrm{R}_{\text {adj }}^{2}=0.99\right)$} & \multicolumn{3}{|c|}{ Max. Volume $\left(\mathrm{R}_{\text {adj }}^{2}=0.99\right)$} \\
\hline & $\mathrm{df}$ & Adj MS & $\mathrm{P}$ value & df & Adj MS & $\mathrm{P}$ value \\
\hline Yeast type & 1 & 522.7 & $0.000 *$ & 1 & 37.5 & $0.002 *$ \\
\hline Dough & 3 & 2010.7 & $0.000 *$ & 3 & 1213.4 & $0.000 *$ \\
\hline Yeast type $\times$ Dough & 3 & 6352.0 & $0.000 *$ & 3 & 839.4 & $0.000^{*}$ \\
\hline Error & 16 & 10.7 & & 16 & 2.7 & \\
\hline
\end{tabular}

Table 2 Maximum leavening rates and volume for the different dough formulations

\begin{tabular}{ll|cccc}
\hline \multirow{2}{*}{ Yeast Type } & \multirow{2}{*}{ Dough } & Max. Leavening Rate & Time & Max. Volume & Time \\
\cline { 3 - 6 } & & $(\mathrm{ml} / \mathrm{h})$ & $30-45$ & $108.3 \pm 0.6^{\mathrm{f}}$ & $(\mathrm{min})$ \\
\hline \multirow{4}{*}{ S. cerevisiae } & $113.3 \pm 2.3^{\mathrm{b}}$ & $30-45$ & $128.7 \pm 1.5^{\mathrm{b}}$ & 105 \\
& Lean & $125.3 \pm 2.3^{\mathrm{a}}$ & $45-60$ & $114.0 \pm 2.0^{\mathrm{de}}$ & 105 \\
& Sucrose & $76.0 \pm 4.0^{\mathrm{d}}$ & $45-60$ & $118.3 \pm 1.5^{\mathrm{cd}}$ & 120 \\
& Lactose & $90.7 \pm 4.6^{\mathrm{c}}$ & $45-60$ & $82.7 \pm 0.6^{\mathrm{g}}$ & 195 \\
\multirow{5}{*}{ K. lactis } & Whey & $25.3 \pm 2.3^{\mathrm{e}}$ & $45-60$ & $113.3 \pm 1.5^{\mathrm{e}}$ & 120 \\
& Lean & $89.3 \pm 2.3^{\mathrm{c}}$ & $30-45$ & $142.3 \pm 2.5^{\mathrm{a}}$ & 120 \\
& Sucrose & $130.7 \pm 2.3^{\mathrm{a}}$ & $30-45$ & $121.0 \pm 2.0^{\mathrm{c}}$ & 75 \\
\hline
\end{tabular}

Error bars indicate the SD of the mean of three replicates $(n=3)$, * Values followed by different small letters $(a, b, c)$ in the same column are significantly different. $(\mathrm{P}<0.05)$ 

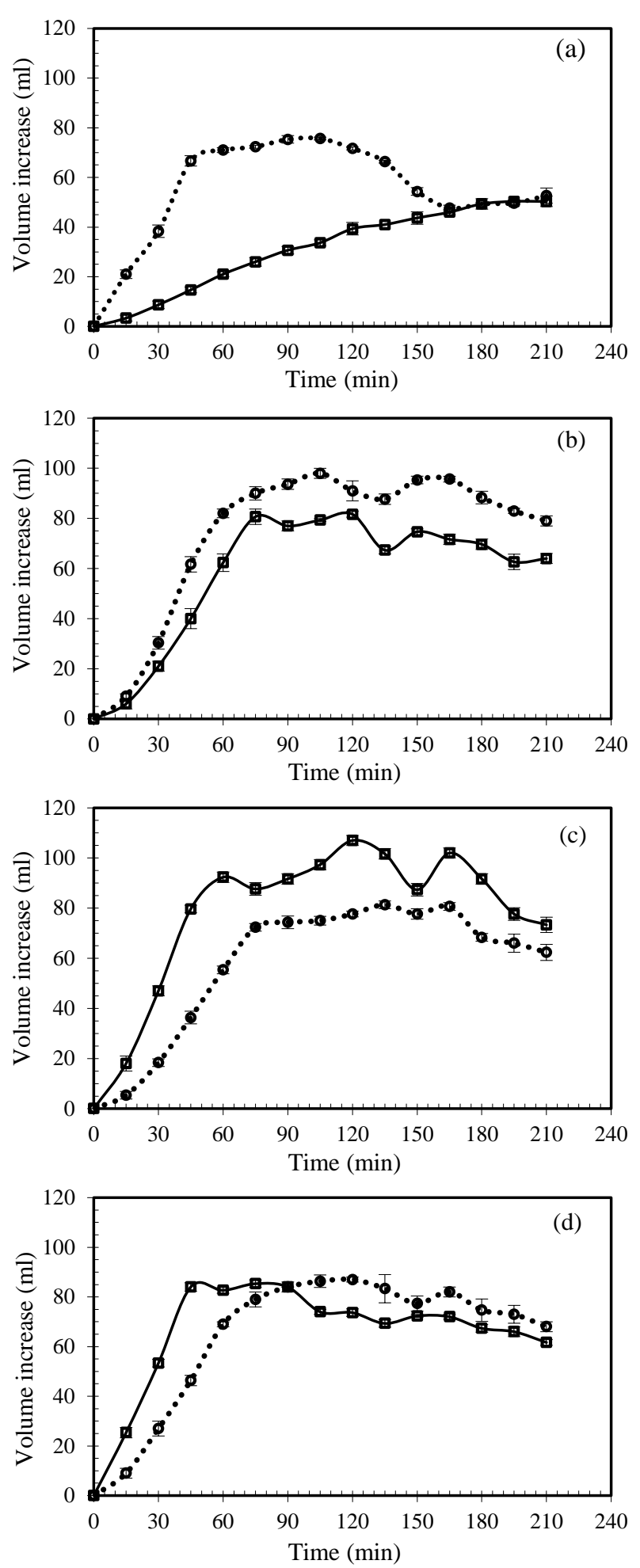

Figure 2 Leavening ability of $S$. cerevisiae (O) and $K$. lactis $(\square)$ in lean dough (a) and in reach dough with sucrose (b), lactose (c) and whey (d)

When considering all results, $K$. lactis provided the highest maximum volume in rich dough with lactose. Maximum leavening ability of $S$. cerevisiae was 4.5 and 1.4-fold greater than $K$. lactis in lean dough and rich dough with sucrose, respectively while maximum leavening ability of $K$. lactis was 2 and 1.4-fold greater than $S$. cerevisiae in rich dough with lactose and whey, respectively. K.lactis has been reported to have lactase activity which may explain its high performance in rich dough with lactose or whey. This performance can be seen in Table 2 and Figure $1 \mathrm{c}$, d as a higher speed of fermentation during the first hour. Maximum leavening rate of S.cerevisiae and K.lactis added doughs were 113.3 and $25.3 \mathrm{ml} / \mathrm{h}$ for lean doughs, 125.3 and $89.3 \mathrm{ml} / \mathrm{h}$ for sucrose containing doughs, 76.0 and $130.7 \mathrm{ml} / \mathrm{h}$ for lactose containing doughs, 90.7 and $122.7 \mathrm{ml} / \mathrm{h}$ for whey containing doughs, respectively (Table 2).

The lowest dough volume and the lowest maximum leavening rate were obtained from lean dough which fermented by $K$. lactis. The results showed that $K$. lactis reached higher leavening rate and volume than bakery yeast in the presence of lactose and whey. When whey was added to the dough instead of lactose, similar maximum leavening rate was obtained, however the maximum volume was lower (Table 2). In present study, addition of the $2.5 \mathrm{~g}$ of whey to rich dough provided $0.7 \%$ increase in protein concentration and the presence of whey protein caused a decrease in maximum volume. Similar observation was previously reported by Zhou et al., (2018). They stated that limited addition (up to 10\%) of whey protein to wheat flour caused a decrease in bread volume. Each protein has its own functional properties (swelling and emulsifying) that specify the structure forming ability of them. It is well known that gluten, the protein component of wheat flour, makes the dough cohesive and extensible, easily sheeted and shaped, in addition to capable of retaining the gases produced during fermentation and proofing. The incorporation of foreign proteins interfered with gluten development and therefore, had negative effect on dough volume.

\section{Conclusions}

Both the yeast type and dough formulation were determined as effective factors on the maximum leavening rate and maximum volume parameters. When we compared commercial bakery strain $S$. cerevisiae to $K$. lactis, leaving ability and maximum volume were determined higher in lean and sucrose-rich dough. On the other hand, $K$. lactis showed better performance in lactose-rich dough and whey-rich dough compared to $S$. cerevisiae. Similar maximum leavening rates were obtained from dough which contains whey or lactose and fermented by $K$. lactis and also, from dough containing sucrose and fermented by $S$. cerevisiae. Therefore, these results demonstrate that Kluyveromyces lactis can be a useful bakery yeast for lactose or whey fortified bread making.

\section{Acknowledgment}

This study was funded by Ordu University (AR 1237).

\section{References}

Ammar AS, Salem SA, Badr FH. 2011. Rheological properties of wheat flour dough as affected by addition of whey and soy proteins. Pakistan Journal of Nutrition, 10(4): 302-306. DOI: 10.3923/pjn.2011.302.306.

Büyükkileci AO. 2007. Analytical Methods. In: Investigation of Sugar Metabolism in Rhizopus oryzae (Ph.D. Thesis) (pp. 24). The Graduate School of Natural and Applied Sciences of Middle East Technical University: Ankara. 
Caballero R, Olguin P, Cruz-Guerrero A, Gallardo F, GarciaGaribay M, Gbmez-Ruiz L. 1995. Evaluation of Kluyveromyces marxianus as baker's yeast. Food Research International, 28(1): 37-41. DOI: 10.1016/09639969(95)93329-S.

Chavan JK, Kadam SS. 1993. Nutritional enrichment of bakery products by supplementation with nonwheat flours. Critical Reviews in Food Science and Nutrition, 33(3): 189-226. DOI: 10.1080/10408399309527620.

Dimitrellou D, Kandylis P, Kourkoutas Y, Koutinas AA, Kanellaki M. 2009. Evaluation of thermally-dried Kluyveromyces marxianus as baker's yeast. Food Chemistry, 115(2): 691-696. DOI: 10.1016/j.foodchem.2008.12.050.

Fuson GB, Presley HL, Phaff HI. 1987. Deoxyribonucleic acid base sequence relatedness among members of the yeast genus Kluyveromyces. International Journal of Systematic Bacteriology, 37(4): 371-379. DOI: 10.1099/00207713-374-371.

Indrani D, Prabhasankar P, Rajiv J, Rao GV. 2007. Influence of whey protein concentrate on the rheological characteristics of dough, microstructure and quality of unleavened flat bread (parotta). Food Research International, 40(10): 12541260. DOI: 10.1016/j.foodres.2007.08.005.

Istianah N, Ernawati L, Anal AK, Gunawan S. 2018. Application of modified sorghum flour for improving bread properties and nutritional values. International Food Research Journal, 25(1): 166-173.

Johannsen E. 1980. Hybridization studies with the genus Kluyveromyces van der Walt emend. van der Walt. Antonie van Leeuwenhoek Journal of Microbiolog, 46(2): 177-189. DOI: $10.1007 / \mathrm{BF} 00444073$.

Johannsen E, van der Walt JP. 1978. Interfertility as a basis for the delimitation of Kluyveromyces marxianus. Archives of Microbiology, 118(1): 45-48. DOI: 10.1007/BF00406072.

Królczyk JB, Dawidziuk T, Janiszewska-Turak E, Sołowiej B. 2016. Use of whey and whey preparations in the food industry - a Review. Polish Journal of Food and Nutrition Sciences, 66(3): 157-165. DOI: 10.1515/pjfns-2015-0052.

Mazı BG. 2010. Dry Weight Determination. In: Evaluating microemulsions for purification of beta-galactosidase from Kluyveromyces lactis (Ph.D. Thesis) (pp. 31). The Graduate School of Natural and Applied Sciences of Middle East Technical University: Ankara.

Okagbue RN. 1988. A note on the leavening activity of yeasts isolated from Nigerian palm wine. Journal of Applied Bacteriology, 64(3): 235-240. DOI: 10.1111/j.13652672.1988.tb03380.x.

Pearson T, Kock JLF, Kilian SG. 1990. The Value of Carbon Compound Mixtures in the Identification of the Yeast Genus Kluyveromyces. Systematic and Applied Microbiology, 13(1): 56-59. DOI: 10.1016/S0723-2020(11)80180-3.
Platt T, Müller-Hill B, Miller JH. 1972. Protein purifications in experiments in molecular genetics. 3rd ed. J.H. Miller (Ed.) (pp. 352-356). Cold Spring Harbor Laboratory: New York.

Plessas S, Bekatorou A, Gallanagh J, Nigam P, Koutinas, AA, Psarianos C. 2008a. Evolution of aroma volatiles during storage of sourdough breads made by mixed cultures of Kluyveromyces marxianus and Lactobacillus delbrueckii ssp. bulgaricus or Lactobacillus helveticus. Food Chemistry, 107(2): 883-889. DOI: 10.1016/j.foodchem.2007.09.010.

Plessas S, Fisher A, Koureta K, Psarianos C, Nigam P, Koutinas AA. 2008b. Application of Kluyveromyces marxianus, Lactobacillus delbrueckii ssp. bulgaricus and L. helveticus for sourdough bread making. Food Chemistry, 106(3): 985990. DOI: 10.1016/j.foodchem.2007.07.012.

Ramachandra B, Manjunath H, Prabha R, Krishna P. 2009. Standardization of bread dough rise capacity using Kluyveromyces Lactis and Saccharomyces Cerevisiae yeast cultures. Journal of Dairying, Foods and Home Sciences, 28(2): 124-126.

Ribotta PD, Arnulphi SA, Leon AE, Anon MC. 2005. Effect of soybean addition on the rheological properties and breadmaking quality of wheat flour. Journal of the Science of Food and Agriculture, 85(11): 1889-1896. DOI: 10.1002/jsfa. 2191.

Rubio-Texeira M. 2006. Endless versatility in the biotechnological applications of Kluyveromyces LAC genes. Biotechnology Advances, 24(2): 212-215. DOI: 10.1016/j.biotechadv.2005.10.001.

Schaffrath R, Breunig KD. 2000. Genetics and molecular physiology of the yeast Kluyveromyces lactis. Fungal Genetics and Biology, 30(3): 173-190. DOI: 10.1006/fgbi.2000.1221.

Sudha M, Rajeswari, G, Rao GV. 2011. Influence of defatted soy flour and whey protein concentrate on dough rheological characteristics and quality of instant vermicelli. Journal of Texture Studies, 42(1): 72-80. DOI: 10.1111/j.17454603.2010.00269.x.

Tang X, Liu J. 2017. A comparative study of partial replacement of wheat flour with whey and soy protein on rheological properties of dough and cookie quality. Journal of Food Quality, DOI: 10.1155/2017/2618020.

Vaughan-Martini A, Martini A. 1987. Taxonomic revision of the yeast genus Kluyveromyces by nuclear deoxyribonucleic acid reassociation. International Journal of Systematic Bacteriology, 37(4): 380-385. DOI: 10.1099/00207713-374-380.

Wesolowski-Louvel M, Breunig KD, Fukuhara H. 1996. Kluyveromyces lactis. In: Nonconventional yeasts in biotechnology. 1st ed. K. Wolf (Ed.) (pp. 139-201). Springer: Berlin.

Zhou J, Liu J, Tang X. 2018. Effects of whey and soy protein addition on bread rheological property of wheat flour. Journal of Texture Studies. 49(1): 38-46. DOI: 10.1111/jtxs.12275. 